\title{
Application of Electroporation Technique in Biofuel Processing
}

\author{
Abu Yousuf ${ }^{1, *}$, Maksudur Rahman $\mathrm{Khan}^{2}$, Amirul Islam $^{2}$, MdMinhaj Uddin Monir ${ }^{1}$, \\ Zularisam Ab Wahid ${ }^{1}$, and Domenico Pirozzi ${ }^{3}$ \\ ${ }^{1}$ Faculty of Engineering Technology, University Malaysia Pahang, Malaysia \\ ${ }^{2}$ Faculty of Chemical and Natural Resources Engineering, University Malaysia Pahang, Malaysia \\ ${ }^{3}$ Department of Chemical Engineering, Materials and Industrial Production, University Naples \\ Federico II, Italy
}

\begin{abstract}
Biofuels production is mostly oriented with fermentation process, which requires fermentable sugar as nutrient for microbial growth. Lignocellulosic biomass (LCB) represents the most attractive, low-cost feedstock for biofuel production, it is now arousing great interest. The cellulose that is embedded in the lignin matrix has an insoluble, highlycrystalline structure, so it is difficult to hydrolyze into fermentable sugar or cell protein. On the other hand, microbial lipid has been studying as substitute of plant oils or animal fat to produce biodiesel. It is still a great challenge to extract maximum lipid from microbial cells (yeast, fungi, algae) investing minimum energy.Electroporation (EP) of LCB results a significant increase in cell conductivity and permeability caused due to the application of an external electric field. EP is required to alter the size and structure of the biomass, to reduce the cellulose crystallinity, and increase their porosity as well as chemical composition, so that the hydrolysis of the carbohydrate fraction to monomeric sugars can be achieved rapidly and with greater yields. Furthermore, EP has a great potential to disrupt the microbial cell walls within few seconds to bring out the intracellular materials (lipid) to the solution. Therefore, this study aims to describe the challenges and prospect of application of EP technique in biofuels processing.
\end{abstract}

\section{Introduction}

Biofuel (biodiesel, bioethanol, biogas, bio- $\mathrm{H}_{2}$ ) is a promising alternative to conventional fossil fuels since it does not have the same environmental impact associated with fossil fuels. Lignocellulosic biomass is considered as a reliable renewable source for the production of biodiesel, bioethanol, biogas and bio- $\mathrm{H}_{2}[1-3]$. The conversion of lignocellulosic biomass to biofuels requires the following common steps: hydrolysis of cellulose and hemicellulose, sugar fermentation, lignin residue separation and finally recovery and purification of biofuels in order to fulfill fuel specifications. The

*Corresponding Author: ayousufcep@yahoo.com,ayousuf@ump.edu.my 
hydrolysis of cellulose and hemicellulose is technically difficult because the digestibility of these two components are hindered by physico-chemical complexities in biomass. These structural complications are the reason why a pretreatment step is necessary for obtaining various chemicals and fermentable sugars during the hydrolysis step. The reason for the implementation of pretreatment is to open up the biomass structure and break down the lignocellulosic bonding in order to promote enzymatic accessibility to cellulose and hemicellulose for hydrolysis[4-6]. Therefore, the pretreatment is a rate limiting step for the conversion of biomass to fermentable sugars, but it has been viewed as one of the most expensive processing steps. The benefits with pretreatment are the great potential for improvement of efficiency of lignocellulosic biomass processing and it can reduce the economic costs as well as facilitate the total biofuel process [4, 6].On the other hand, microbial oils are considered as substitute of plant oils to synthesis biodiesel. Microalgae and yeast are the main source of microbial oils but extraction of oils from those is a challenging step. Existing processes are associated withhigh cost, large volume of solvent and time consuming.

Electroporation (EP) is a microbiologicaltechnique, which involves application of a short burst of high voltage to a sample placed between two electrodes. EP treatment has serious effects on the structure of biological tissues [7]. When a high-intensity, external electric field is applied, a critical electric potential is induced across the cell membrane, which leads to rapid electrical breakdown and local structural changes of the cell membrane and the cell wall[8]. The electric field results in a dramatic increase in mass permeability and, in some cases, mechanical rupture of the plant, animal or microbial tissues. Application of high-intensity electric field pulses from nanoseconds to microseconds in duration leads to the permeabilization of biological membranes. This technology is massively using in food industry and genetic engineering. The fractionating characteristics of EP and its high efficiency can overcome current processing difficulties for biofuel applications [7]. This study describes the pathway of EP application to enhance the biofuel production focusing its limitations and prospects.

\section{EP in biogas technology}

There is a large potential of biogas production from different kinds of organic residues as well as from different crops, farmland residues or organic solid waste. These residues are abundantly available and is in many cases seen as a problem instead of what they really are, a resource. Currently biogas plays a minor, but steadily growing its role in renewable bioenergy sector. However, the technology for biogas production is still developing and not yet optimized and thus not fully cost-effective. To be fully commercially competitive with other types of fuels, efficiency improvements of the process is urgent. Recently, commercial biogas is producing from agriculture (energy crops) and forest wastes, i.e., from lignocellulosic biomass. Although, the source of lignocellulosic biomass is abundant in almost every country, their contribution in RE sector is insignificant. Lignocellulosic biomass is composed of carbohydrate polymers (cellulose and hemicellulose) and lignin. Typically, LCB contains 35-55\% cellulose, 20-40\% hemicellulose and 10-25\% lignin [2]. The pre-hydrolysis, often referred as pretreatment, is required to alter the structure of lignocellulosic biomass to make cellulose more accessible to the enzymes that convert the carbohydrate polymers to fermentable sugars. Structural change of lignocellulosic biomass is the rate-limiting step for the conversion of lignocellulosic biomass to biogas. This change will reduce the retention time and increase the production rate. EP technique can be applicable to disrupt or deform the structure of cellulosic biomass. The mechanism of EP is illustrated in the Fig. 1., where biomass is placed between two electrodes with a short burst 
of high voltage. As a result, biomass structure is deformed or destroyed by the high electric field.

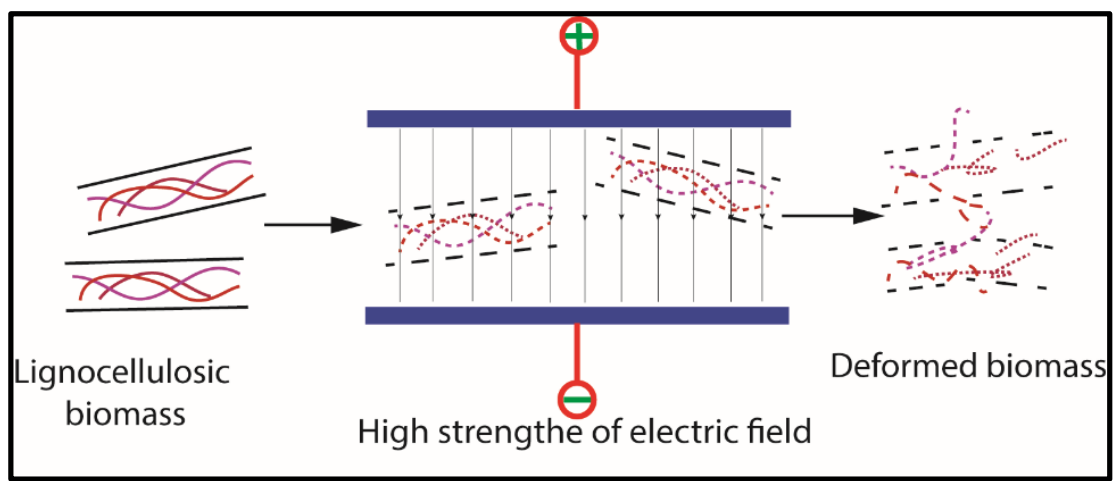

Fig. 1. Conceptual effect of EP on lignocellulosic biomass.

Garoma and Shackelford [9] applied EP as a pretreatment method for algal biomass used as feedstock for anaerobic digestion. They were able to increase bio- $\mathrm{CH}_{4}$ production as high as $110 \%$. Lindmark [10] studied the effect of EP on lay crop silage to enhance the biogas output and the data from the electroporation experiments show an increased gas production of over $100 \%$ during 36 days of fermentation. Though, EP has shown its potentiality over the biological cell destruction, its application in biofuel sector is still limited.

In recent year, dry fermentation or solid-state fermentation (SSF) has attracted the attention due to its various advantages over wet fermentation, such as it requires smaller volume of digester, no water addition, no mechanically stirred, no dewatering or drying of the effluent. The commercial biogas plant, where single type substrate (energy crop, forest residue) is used, EP technique may be applicable (Fig. 2.) to boost up the biogas production and reduce the retention time and processing cost.

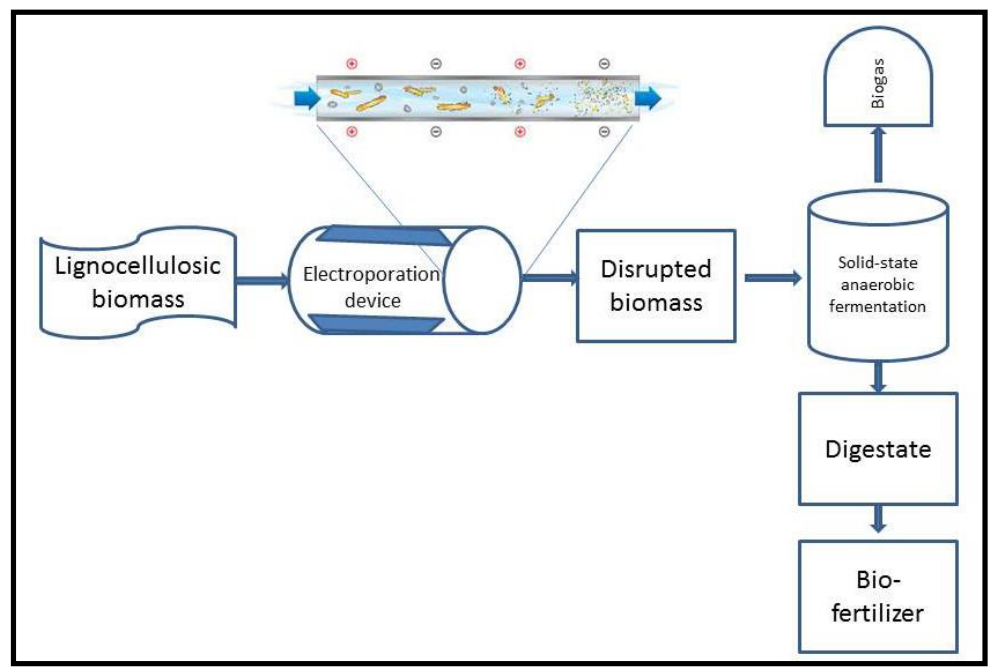

Fig. 2. Simplified process diagram of EP and SSF. 


\section{EP in biodiesel processing}

In recent times, biodiesel production from microbial oils or single cell oil (SCO) has become very widespread. Most attractive candidates for this purpose are microalgae and yeasts. The challenging part of the biodiesel synthesis from SCO is the extraction of microbial oils from intracellular compartments. EP can be applied in the stage of oil/lipid extraction process. In traditional way, microbial biomass is dried, added solvent and applied physical forces (glass bed, ultrasonic sound etc.) to disrupt cell wall to extract lipid. Afterward lipid is separated and carried out esterification to synthesis biodiesel. However, implication of EP can simplify the process offering financial and environmental benefits, since the technique works for nano- to micro-second, it consumes lower amount of energy.

Applying EP, transesterification can be done in situ, also called direct transesterification, where reaction is carried out in a single step (Fig.3). EP technology enhances the transesterification process producing pores in the microbial cells by exposing the substrate to electrical fields. During the treatment, the cells are damaged and releases nutrients that can lead to an increase in the biodiesel production rate.
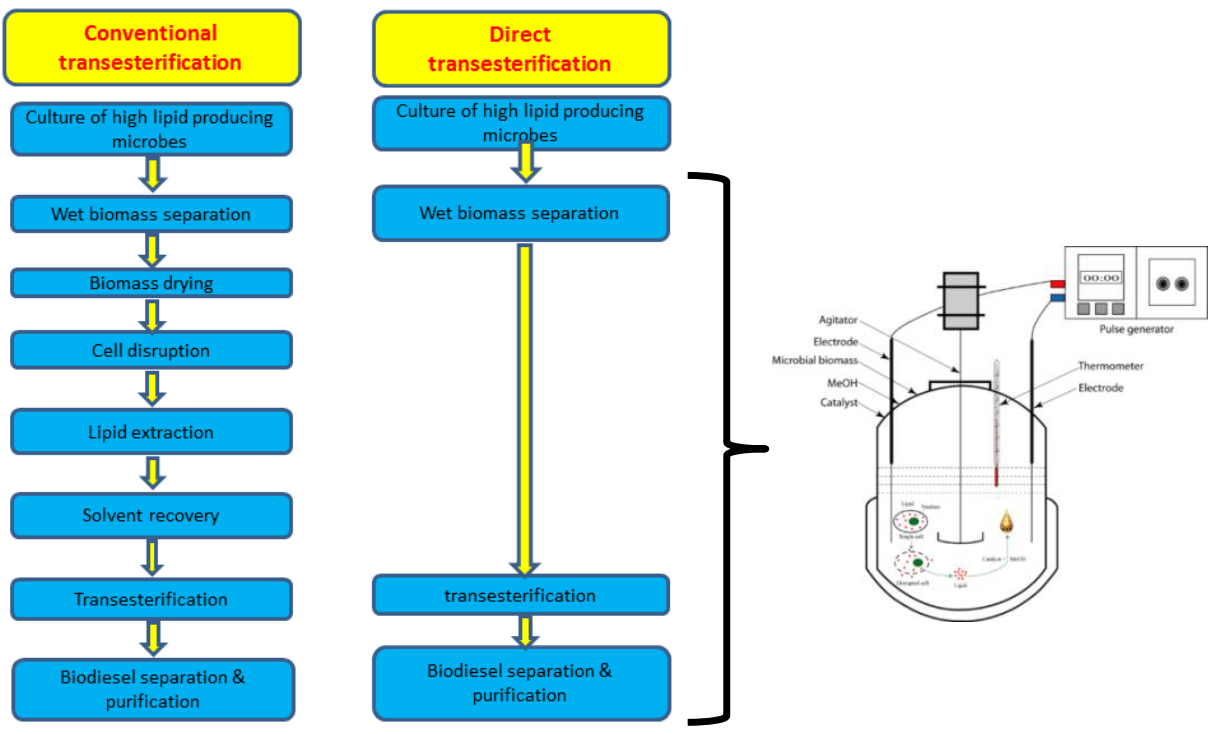

Fig. 3. Application of EP for direct transesterification of microbial lipid to synthesis biodiesel.

A feasibility study of electroporation as a pretreatment method has been conducted by Garoma and Shackelford [9] for algal biomass used as feedstock for anaerobic digestion. Electroporation of cells results in a significant increase in cell conductivity and permeability caused due to the application of an external electric field. They also reported that pretreating algal biomass with electroporation significantly improved the soluble COD (SCOD), increasing it to more than $830 \%$ at $28 \mathrm{kWh} / \mathrm{m}^{3}$ treatment intensity (TI). Addition to TI, culture conditions also influenced the performance of the electroporation process. According to Lindmark [10], the reaction container, electric current, the distance between the electrodes and the number of pulses have also effect of electroporation on the treated material. The cell disruption can be maximized using EP technique by keeping the lowest level of TI and solvent volume [11]. 


\section{Conclusion}

In summary, integration of electroporation technique in biogas and biodiesel processing has offered promising results for lowering the costs and environmentaleffects of the solventbased extraction step. The optimal strength of the electrical field depends on the type, size and geometry of the cell tissue. In addition, the intensity of the field, the frequency of the field and the geometry of the pulses probably has an impact on the result.

The University Malaysia Pahang has supported this research under the project RDU1403148.

\section{References}

1. N. Ren, W. Guo, B. Liu, G. Cao, J. Ding, Curr. Opin. Biotechnol., 22, 365 (2011)

2. A. Yousuf, Waste Manage., 32, 2061 (2012)

3. S. Chaikitkaew, P. Kongjan, S. O Thong, Energy Procedia, 79, 838 (2015)

4. D. Chiaramonti, M. Prussi, S. Ferrero, L. Oriani, P. Ottonello, P. Torre, F. Cherchi, Biomass Bioenerg., 46, 25 (2012)

5. P. Kumar, D. M. Barrett, M. J. Delwiche, P. Stroeve, Ind. Eng. Chem. Res, 48, 3713 (2009)

6. J. Ariunbaatar, A. Panico, G. Esposito, F. Pirozzi, P. N. Lens, Appl. Energy, 123, 143 (2014)

7. T. Kotnik, W. Frey, M. Sack, S. Haberl Meglic, M. Peterka, D. Miklavcic, Trends Biotechnol., 33, 480 (2015)

8. R. Joshi, K. Schoenbach, Phys. Rev. E, 62, 1025 (2000)

9. T. Garoma, T. Shackelford, Bioresource Technol., 169, 778 (2014)

10. J. Lindmark, The Biogas Optimization Project, (Malardalen University, Vasteras, Sweden, 2013)

11. J. Sheng, R. Vannela, B. E. Rittmann, Environ. Sci. Technol, 45, 3795 (2011) 